professional personnel. It was generally agreed by a capacity attendance that the conference meetings were among the most productive ever held in the community.

While it may be safely stated that the declared objectives of the conference were realized in full measure, it must not be inferred that a single cooperative undertaking establishes for all time the success of a continuing program of community development. There are, however, latent in such situations, important elements which, when skillfully utilized, become invaluable tools for the adult educator in meeting new problems.

In addition to achieving the listed objectives through the medium of the conference sessions, possibly the most valuable outcome, from the professional standpoint, was the acceptance of the leadership of adult education in the vital area of community development. In the eyes of this community, adult education no longer is concerned merely with providing constructive leisure time activities for individuals, preparing the foreign- born for American citizenship, and helping industrial employees to acquire new mechanical skills. Adult education has finally "come of age" and is now recognized as a full partner in the significant affairs of community life.

The illustration of a successful conference has not been cited as an isolated instance of a cooperative community endeavor, but as an outstanding example among several which could be used equally well to make a point for which the limits of this article do not permit more extensive development. The adult educator in his daily tasks enacts not one but many roles, and of these, that of salesman for his product overshadows all others. Unless the professional adult educator is able to develop ideas worthy of the serious consideration of his community's most mature lay leadership and then provide the skill necessary to build a functioning team for direct attack upon the problem under consideration, little hope can be entertained for this working partnership which is so indispensable for community adult education.

\title{
comments and reactions
}

From 7 Leaders in the Fields of Social Welfare and Community Organization

\section{Walfer Wenkert}

Secretary, Health Division, Council of Social Agencies, Rochester, N. Y.:

I read the manuscript on the Role of Adult Education in Community Development twice to discover why I agreed with the principles of com- munity development it outlined, but maintained an aloof and resistant attitude through both readings, and I think the reason for my attitude lies in the psychology of the five contributors. They do not include me in their select society. In the words of the preface: "the central roles adult educators and adult education agen- 
cies are coming to play in community development projects". I am out in the cold!

Mr. Johnson carries your theme further when he says the adult educator must provide the intellectual leadership and "initiate a group which will make the formulation of this conceptual framework a central task". And so on and so on.

One of the most helpful educational experiences I have had was to sit in on a conference at which experienced community organizers whose basic training had been in social work, and health educators whose training had been in public health battled on this problem of who organizes community thinking and planning for mental health. I learned from this conference that the training of teachers and social workers and health educators and many, many others have more similarities than differences. That if we have a job of working with people for community development, then none of us can afford to be the "chosen people". This is especially true when those of us who have definite program areas as our major responsibility are so many -and the theoretical "adult educator" who coordinates just everybody seems to be lacking in most of our communities.

Your symposium prompts me to look into the possibility of discovering whether adult education leadership is available for community planning efforts. (I am new in this city and state.) I would suggest that the adult educators will gain more converts if they would preach with just a touch of the humility all of us who work with people need to have.

\section{Albert G. Rosenberg}

Executive Secretary, Area Councils

Project, Dayton, Obio:

I am basing my comments on the definition of "community development" as contained in the symposium preface: "programs, whatever their names and sponsorship, which stress citizen participation in the improvement of their physical and social environment", and on the use of the term "adult education" by the contributors in the narrower sense of the word, as: not including "other professions which can from time to time make major contributions to the community development"-such as the "doctors, lawyers, soil conservation experts, social workers, clergymen, teachers and others" partially listed in one of the discussions.

One of the most encouraging developments of recent years has been the broad and steady progress made at agency operation and professional training level of the various professions and disciplines which are found to operate in the community development area. Today, for instance, the better schools of public health put strong emphasis on giving their students a solid foundation in the philosophy of citizen participation in community health programs and teach them the basic skills and methods of how to effectively facilitate such participation. The same is happening in other fields, prominent among them being public education, social work, intergroup relations, to list just a few. To be sure, it has taken a long time, and a history of failures and frustrations for the various fields to learn the facts of life and come to see that their efforts 
often fail to produce fullest dividends because the community is not properly involved, and to recognize that to have this happen definite skills must be available to the practitioners in the various fields-firmly based on the foundations of a healthy philosophy which calls for community partnership in their efforts. We know that we have a long way to go yet, and there is still much we need to learn and develop in the area of the techniques and methods of what is often called "community organization". Some professions and agencies are more advanced than others, but I am convinced we are moving in the right direction.

When a community development program for instance involves the function of a public health agency, then a public health person is needed to provide staff service for such a program, including its community participation phase. Or when a community development program falls into the area of function of social welfare agencies, then the social work staff of that agency has also the responsibility to involve the community.

I sharply disagree with the suggestions of some adult educators who see adult education's roles in community development to be that of intermediary between the agencies and the community-to be the facilitators of citizen participation in community development programs. Such a development would be a big step backward and entirely in the wrong direction. Some symposium contributors see adult education in "the central role" in community development. Mr. Johnson refers to the "switch- board function ... to put people and agencies in touch with each other"; Mr. Dickerman sees adult educators as "facilitators in the "catalytic' sense"; Mr. Oliver speaks of the adult educator as "the 'idea' man or the 'energizer' to provide initial impetus to a chain reaction" ... "wholesaler of ideas". Reading the symposium, I get the impression that some of the contributors are possibly not aware of the developments which for years have been occurring in the various fields and that they believe that unless adult educators see to it that it happens, there will not be citizen participation in community development programs. It is impossible to accept as valid and factually correct, for instance, Mr. Johnson's statement that it is the adult educator's "central task" in a program of community development to "provide the intellectual leadership without which the program will be a shallow one, producing no significant growth in either individuals or communities". Let me make reference only to the field of social work which over a period of decades has developed the professional practice of "community organization for social welfare". In many large and medium sized cities across the country autonomous community, neighborhood, and district councils, receiving staff service from social workers who are experts in the field of community organization, facilitate effective citizen participation in social welfare programs in their neighborhood and wider community. In the process, individuals and communities not only achieve social goals but also experience a healthy individual and community growth 
and change process. These councils are quite different from the community councils of adult education which, according to Morse Cartwright's chapter on adult education in the '54 Encyclopedia Americana, "serve as local clearing houses of information about educational opportunities".

Citizens participation in community affairs and development programs is vital for the healthy development of the American community. These programs involve many professions and disciplines, which must, and are in fact doing so, increasingly recognize the importance of citizen participation and learn how to make it become a reality. However, no one field, as it is suggested in some of the contributions to this symposium, should usurp the role of the "facilitator" of this needed citizen participation.

Adult education is one among a number of professions which has a major contribution to make to community development-within its own proper function-but it seems to me this needs to be spelled out more clearly.

\section{Arthur Dunham}

Professor of Community Organization, School of Social Work, Univsity of Michigan:

A recent United Nations report on Principles of Community Development seems to me one of the most exciting documents yet published on this subject. It defines community development as a "process designed to create conditions of economic and social progress for the whole commu- nity with its active participation and the fullest possible reliance upon the community's initiative". It also outlines 10 "basic elements" or principles of community development. Several of these principles echo the experience of adult educators-activities in response to "felt needs", multi-disciplinary teamplay, citizen participation (including "women and youth"!) leadership training, and skillful use of resources. But one principle in particular surely goes to the heart of the faith of the adult educator: "Changed attitudes in people are more important than the material achievements of community projects."

From where I sit, as a teacher of community welfare organization, most of the material in the present symposium seems to make sound and substantial sense. Having said this, let me offer four comments and suggestions some of which do not coincide with the views of some of the symposium participants.

1. Adult educators and social-work c om mu nity organization workers (not manipulative "community organizers", please!) have much in common when they become involved in community development. However, as I see it, there is also a fundamental difference between them. The social worker is concerned primarily with helping people meet their community social welfare needs. The adult educator, I assume, is concerned primarily with the process of citizen education.

2. The adult educator, as I understand it, is an expert in educationparticularly in adult education. This is a great and glorious field of effort. But the adult educator is not, except 
by chance, in individual cases, an expert in such substantive areas of content as public health, school administration, agriculture, safety, law enforcement, juvenile delinquency, village festivals, or public recreation programs. It always disturbs me if I see an adult educator trying to function as a professional consultant for a content area where he doesn't have any expertness!

I can see an adult educator serving appropriately as the professional consultant for a community adult education council. I am much more doubtful about his being an appropriate professional consultant on program for a general community council whose major focus is on meeting community needs through integrated and cooperative effort. As "experts" or specialists (including, by all means, the social workers), let's keep to our respective "areas of competence"! The world is so full of a number of things that I view with alarm even a slight tendency toward omniscience on the part of any one of our really rather limited professions. All of us working together don't really know enough to give communities the help they need and deserve.

3. I would take the most vigorous exception to the idea suggested by one contributor to the symposium, that the adult educator is to furnish "the intellectual leadership" for the program of community development. If any profession starts out with the idea that is called upon to furnish the "intellectual leadership" in community development, it might as well stop talking about teamwork with other professions. The "intellectual leadership" will have to come partly from the community residents themselves and partly from a variety of professionals-if it doesn't, we'd better call off the whole collaborative idea!

Incidentally, the suggestion that someone must "conceptualize the community" (see it whole) is sound enough, but doesn't this particular need require essentially the expertness of the sociologist rather than that of the adult educator? Is the adult educator, after all, an expert in communities and total community life, as such?

4. More and more, I am beginning to suspect that perhaps we need a new kind of professional that doesn't exist today-or at least doesn't have a recognized discipline. We need, I begin to think, a specialist in general community development. This sounds like an Irish bull, but actually he would specialize in being a generalist! Such a generalist would need a lot of equipment of the adult educator. $\mathrm{He}$ would need much of the knowledge and skill of a well-qualified community welfare organization worker -his understanding of problem analysis, surveys, planning, interviewing, conference, consultation, organization, administration, and particularly program and project development. In one sense he would be a specialist in community organization and educational methods. He would need also to know a good deal more than, probably, either the social worker, or adult educator usually knows, about special aspects of community life and areas of content as different as agriculture, public health, public education, and public administration. We are familiar with the idea of multi- 
purpose village workers" in less developed areas. Are we here describing a "multi-purpose professional"? Is this a contradiction in terms? Obviously this person can't become an expert in half a dozen content areas; but he might learn to "find his way around" in each of them, to understand basic concepts, objectives, and resources; to be able to give directly certain types of help and consultation, to recognize situations which were beyond his competence, and in those cases to help citizens connect up with other more technical resources. It is not at least thinkable that adult education, social work, public health, and a number of other disciplines might unite in exploring the possibilities of a real inter-departmental program for training a new type of professional consultants in community development?

\section{Charles E. Hendry}

School of Social Work, University of Toronto:

I am grateful for the opportunity to preview this symposium. The five statements included reflect a considerable range of vital experience in relation to community development. On the whole they are most thoughtful and at several points quite penetrating. It is not difficult to detect where there has been a beneficent blending of deeply insightful educational philosophy and of promising new developments in the application of behavioral sciences.

The crucial point, as I see it, is made by Hoiberg. The focus of the so-called professional worker is process-oriented, not program-oriented.
The relationship is essentially that of consultant, embracing such interrelated roles as guide, enabler, expert, and, under certain appropriate conditions, therapist.

I question whether Johnson is justified in suggesting that educators are the only profession "likely to have the whole community in mind". Many persons in many professions are trying hard to see the community as a whole. Incidentally, in his $T$ he Public Pbilosophy Walter Lippmann has an eloquent and instructive passage on THE PEOPLE as differentiated from The People that is highly relevant to this discussion.

In my view there is both an "adult education" and also a "community organization" component in each and every human service profession. "Intellectual leadership" cannot be delegated to any one group. The need for a high level of "conceptualization" is present in every profession.

I wonder if I am correct in concluding that there is a significant difference between the way in which Johnson develops his notion of "intellectual leadership" and Oliver's notion of the "idea man" selling ideas to the community. Also, I find myself reacting quite negatively to the use of "capacity attendance" as a criterion of effectiveness.

It is good to note that we are moving away from outworn and outmoded concepts of leadership. Johnson's discussion of leadership is most reassuring. Increasingly, as a result of newer research in this area, we are beginning to realize that what we must concern ourselves with is not leadership of groups but the leadership structure of groups. The mo- 
ment we adopt this frame of reference Mial's description of the training Workshop at Syracuse University on Community Organization for Action takes on heightened significance. Here the training experience served three different professional groupseducation, health, and social work. Mial is right, "To be effective in the community, training has to cross professional boundary lines."

Research, action, and education all are intermingled in community organization, and community organization is a process in which practitioners in many different professions require much more systematic knowledge and disciplined skill. This symposium is a positive step in the right direction. A n o the r contribution which I may be pardoned in mentioning is a volume written by one of my colleagues, Murray G. Ross, entitled Community Organization: Theory and Principles, to be published by Harper's this fall. We have a long way to go to escape the provincialism of our various settings and indeed the professionalism of our several professions. Somehow we must rediscover and reaffirm our essential interdependence as we confront common human needs within the context of whole communities.

\section{Eva Schindler}

Personnel Service Director, Girl Scouts, Los Angeles Council:

As a professional social worker who has learned much through collaborating with adult educators in community development, I am delighted to participate in commenting on this symposium. I certainly agree that adult education and adult educators have an important role in community development today. Meshing Otto Hoiberg's and Eugene Johnson's statements, the role of the adult educator seems to be that of providing the "intellectual leadership" which helps people learn how to make their efforts towards community improvement fruitful. I think the "intellectual leadership" is particularly important because the adult educator possesses an important body of knowledge and skills. It is through the able use of this knowledge and these skills that the adult educator often effects meaningful collaboration with other professional people interested in community development.

However, I feel along with Eugene Johnson that the adult educator has more than one role to play. He may carry the primary role of consultant and catalyst with a group or, as $\mathrm{H}$. Curtis Mial puts it, the adult educator may be the initiator, explorer, or consultant. But I think there is something beyond this in the conceptualization of the role of the adult educator, namely his professional responsibilities and obligations to the other professional workers in the community. This means not only that he knows who the professional workers are (ministers, social workers, librarians, etc.), but also that he knows something about them, such as their areas of specific competence; the degree to which these people are accepted by, and reflect their community; the degree to which they are aware of, and able to do something about, their community needs.

For the adult educator's means of collaboration is a two way propo- 
sition. He gives supporting and sometimes initiating help directly to the community development group and he also communicates directly with other professional people, thus fruitful, healthy collaboration depends on the recognition and inclusion of concerned professional and lay people in the community. As I see it, the adult educator listens, analyzes, and consults so he can describe the situation as it exists in this particular community at this time, and thus becomes a more effective consultant with a broad base from which to operate.

At the same time that I recognize the important contribution of the adult educator to community development, I disagree with Eugene Johnson's statement that "only education at the present stage of things is likely to have the whole community in mind", and that therefore "the adult educator must also perform a switchboard role". My experience and a study I did lead me to disagree with this assumption." For intance, the social community organization worker who helps a community development group form and plan for better services for themselves and their children has the whole community in mind as he puts people and agencies and other resources in touch with one another. Specifically, a representative group of community people came together to discuss their concern over inadequate street lighting. The social community organization worker helped the group learn how to make this concern felt and heard by those who could help. From this successful effort the group went to work on other community concerns. They succeeded over a period of time in securing a prenatal clinic, a better library, a more adequately equipped and supervised playground, and some special adult evening classes. Starting with a particular, recognized need, the worker helped the group look at their whole community. As they did so, the group members involved more and more lay and professional people as members, catalysts, and consultants. In the end many of the people affected by the community improvements had also helped to bring them about.

I trace this example because I feel it is important to note that others such as the social worker here may play a role similar to that of the adult educator in community development. It is important that we not categorize people into pigeon holes. Specialists gain valuable insights in their daily contacts with people who may be completely outside their specialty. So, in our collaborative efforts in community development, it is important to remember that there is much other professional workers can learn from the adult educator, and there is also much the adult educator can learn as he analyzes the "chemical composition" of each community and of each community development project group. If such analysis is made carefully, the adult educator can handle himself and his knowledge in such a manner that he becomes a catalytic

\footnotetext{
${ }^{1}$ Eva M. Schindler, "The Roles of Social Group Workers and Educators in Adult Education". A Thesis presented to the Faculty of the School of Social Work,

The University of Southern California, Los Angeles, June, 1954.
} 
agent in the solving of community problems. Perhaps it is time to stop amidst the rush and see what has been missed along the way that would enrich the life and work of the educator as well as those whom he educates.

\section{Joseph H. Douglass}

Assistant to the Assistant Secretary for Program Analysis, U. S. Department of Health, Education and Welfare:

In reading the statements of the conceptions of the several members of the symposium as to the roles of adult educators in community development, I find that I am in general agreement with all of the observations advanced.

What I gain from the discussion, if I understand the consensus of the papers correctly, is that the adult educator has a major role in community development of working with citizens in helping to motivate them to work toward and for their own and the community's improvement. In doing so, he acquaints the individuals and groups with their resources and problems; and in relation to these, assists them in understanding the processes of community development and their individual roles in these processes. This approach is not the same as one of going into a community and helping to organize the individuals and several groups to go forward with action programs. Whereas it may be expected that action will follow sufficient motivation, the techniques and processes for such action on the part of community groups are proper roles for groups and agencies in the community other than the adult educators.

If this role of the adult educator is, in broad outline, definitive, I should think that it would lead to the maximum fruitful collaboration with the other groups in the community. Necessarily, in the performance of the role of providing information, of acquainting people with community resources, and of the citizens' own roles as participants, the adult educator must relate himself to the operating groups in the community, as otherwise his objectives cannot be realized. Once the groups learn that the adult educator is in reality providing assistance to their own objectives through interpreting their purposes, I would be inclined to think that these groups would collaborate with the adult educator in every possible way.

Several observers recognize the "unreached" as a large group in every community-those individuals who for some or several reasons do not seem to participate to any great degree in the processes of community life, and who, perhaps in part because of this, are in greatest need of services which the community attempts to provide. We know that if our democratic life is to reach its highest potential, the reservoir of the potential contribution of these people must be tapped. If adult educators stake out this area as their province and as the one in which they are going to concentrate their efforts in the stimulation of intellectual motivation, in the interpretation of the community's resources and its problems, and in demonstration of how the individual 
can relate himself to others in the accomplishment of common objectives, I feel reasonably certain that they will not only provide a most vital and needed service, but that they can count on the cooperation of all the dedicated groups and individuals which a community affords.

\title{
an institutional approach to adult education in the community
}

\author{
Robert M. Smith and John MeKinley \\ Field Consultants, Community Services in Adult \\ Education, Indiana and Purdue Universities
}

Uppermost in the minds of many of us who have experimented with community development is the problem of insuring the development of people. If community development is to be primarily adult education, then its worth as a means must be measured in terms of its efficiency in assisting individual and group growth in desirable directions: Presumably in such directions as (1) increasing acceptance of civic responsibilities (2) increasing commitment to personal and professional growth (3) increasing ability to see larger social relationships and the personal responsibilities they entail (4) increasing insight into the interdependence of individuals and groups with all of the implications of this concept (5) increasing capacity for purposeful action based on the realities of the situation at hand.

It also seems evident that development activities in a particular community ought to produce a growing number of persons who are moderately well-equipped to deal with problems that confront the community after the cutting back or withdrawing of professional assistance. It follows that community development activities not only need to uncover and develop promising lay leadership but ought also to establish permanent but flexible educational patterns and frameworks within the communities where the university has had its innings.

Emphasis on the growth of individuals raises the problem of insuring that community development programs evolve more or less "naturally". We know that education is perforce a slow process, that people learn at different rates and "when they are ready". Thus the huge "classrooms" of learners that are a community development project must be carefully guided through an evolutionary process. An effective policy should insure against the generation by the community development activities themselves of prohibitive numbers of new problems and obstacles to growth in desirable directions.

These and other reflections based in part on research have led to the conclusion that there is a need for an education-centered approach to community development which can 